Александр Бугровский

\title{
ВСЕРОССИЙСКИЕ ОБЩЕСТВА ЛЮДЕЙ С ИНВАЛИДНОСТЬЮ: ПРИРОДА ИНЕРЦИОННОСТИ ВО ВЗАИМОДЕЙСТВИИ С ОРГАНАМИ ВЛАСТИ
}

В статье исследуется феномен инерции, обеспечивающий неизменность взаимодействия государства и всероссийских обществ инвалидов по вопросам социальной защиты. В российском контексте сохраняются консервативные тенденции во взаимодействии органов власти и НКО: существует патернализм и категориальная помощь людям с инвалидностью, формализм, присущий консультациям с органами власти. Вместе с тем происходит развитие социальных услуг и их поставщиков, внедрение инноваций в рамках политики нового публичного управления. Государство ориентировано на поддержку и развитие третьего сектора, однако всероссийские общества инвалидов с трудом вписываются в современную модель социальной политики. Российское гражданское общество успешно сохраняет сложившуюся структуру и устоявшиеся формы взаимодействия с органами власти. При этом возникает двойственность осуществляемой социальной защиты инвалидов, а именно сохранение инерции при попытках реформирования. В статье рассматривается вопрос о том, какова сущность этой инерции. Цель статьиизучить проявления институциональной инерции на примере взаимодействия государства и всероссийских обществ инвалидов в контексте социальной защиты. На основе теории исторического институционализма, эффекта колеи, идеи об институциональной устойчивости определен термин институциональной инерции, операционализированы индикаторы инерции, проведен анализ деятельности всероссийских обществ инвалидов и составлена матрица ключевых инерционных практик. Источниками данных являются законодательство о защите инвалидов, документы о государственном финансировании обществ,

Александр Игоревич Бугровский- стажер-исследователь, Центр сравнительных исследований власти и управления, Национальный исследовательский университет «Высшая школа экономики», Санкт-Петербург, Россия. Электронная почта: abugrovskiy@hse.ru 
архивные материалы статей, глубинные интервью, ежегодные отчеты о деятельности обществ с 1996 по 2019 гг. На примере информационной, консультативной, имущественной и финансовой поддержки демонстрируется наличие индикаторов институциональной инерции. Выявленные индикаторы подтверждают наличие институциональной инерции во взаимодействии всероссийских обществ инвалидов с государственной властью. Анализ инерционных процессов в институтах социальной политики способствует определению механизмов воспроизведения феномена инерции.

Ключевые слова: третий сектор, социальная защита, новое публичное управление, институциональная инерция, люди с инвалидностью

DOI: 10.17323/727-0634-2021-19-4-685-700

Противоречивость современной российской социальной политики определяется существованием структурных дисфункций, инерционностью социальных институтов (Малева, Авраамова 2017:560), а также неравенством в доступе к государственной поддержке организаций третьего сектора, среди которых особое место занимают общества людей с инвалидностью (всероссийские общества инвалидов, слепых, глухих: далее ВОИ, ВОС, ВОГ). Инерционность их деятельности обеспечивает неизменность их взаимодействия с государством в условиях современной модели социальной политики. Предметом анализа в статье является феномен инерции во взаимодействии государства и ВОИ, ВОС, ВОГ в контексте социальной защиты инвалидов с 1996 по 2019 гг. Феномен инерции проявляется как внутри исследуемых организаций, так и во взаимодействии организаций с внешними акторами. В фокусе исследования- взаимодействие обществ с государственной властью, которая вводит практики нового публичного управления, но одновременно сохраняет консервативные тенденции во взаимодействии с НКО (патернализм и категориальную помощь социально-уязвимым группам граждан, в числе которых люди с инвалидностью).

Противопоставление концептов нового публичного управления и инерции прослеживается в теории и на практике. Если в основе первого лежит принцип конкурсной поддержки и конкуренции социально значимых проектов, то концепт инерции предполагает централизованное государственное субсидирование и выборочную поддержку организаций вне конкурентной системы (Fröhlich, Skokova 2020). Новое публичное управление предполагает прозрачность вводимых государством мер, реальное участие граждан в процессе принятия решений (Lane 2000), что маловероятно при длительной инерции институтов. В России государство стремится оптимизировать деятельность общественных организаций через выстраивание плана действий для достижения конкретных результатов. На практике проявляется статизм в виде поддержки выбранных государством НКО (Tarasenko 2018). Даже в контексте развития доступных 
социальных услуг и их поставщиков, зарождения конкуренции, внедрения технологических инноваций, ВОИ, ВОС, ВОГ сохраняют исторически сложившиеся организационные формы и практики взаимодействия с государством. Таким образом, возникает двойственность социальной защиты инвалидов - а именно, сохранение инерции при попытках реформирования,- которая требует научного анализа и ответа на вопросы, какова сущность инерционности и почему всероссийские общества инвалидов замерли в старой форме в изменяющемся контексте.

Цель статьи - изучить проявления институциональной инерции на примере взаимодействия государства и всероссийских обществ инвалидов в контексте социальной защиты. Для этого далее формулируется теоретическая модель институциональной инерции и выявляются ее ключевые характеристики. Затем операционализируются индикаторы инертности в социальной защите инвалидов на уровне взаимодействия выбранных объектов исследования с государственной властью. Наконец, определяется наличие индикаторов инертности в деятельности организаций инвалидов по социальной защите их подопечных. Источниками данных выступают законодательные акты о социальной защите инвалидов, документы о государственном финансировании этих обществ, ежегодные отчеты о деятельности ВОИ, ВОС, ВОГ и экспертные интервью. Исследование инерции в контексте социальной защиты инвалидов расширяет понимание институциональных процессов и «эффекта колеи» в социальной политике, а фокус на всероссийских обществах инвалидов представляет их деятельность в современной повестке дня.

\section{Подходы к определению институциональной инерции}

Две характеристики сохранения институциональной инерции-устойчивость и непрерывность норм и правил-представлены в концепте эффекта колеи, теории исторического институционализма и идее об институциональной непрерывности. Концепт эффекта колеи объясняет устойчивость и непрерывность институтов тем, что любая деятельность зависит от ранее принятых решений в обществах, вставших на определенную колею развития (Campbell 2010; Pierson 2000). Следующие колее институты coxраняются в течение длительного времени, ограничивают диапазон вариантов решений и исключают альтернативы в долгосрочной перспективе (Mahoney, Thelen 2010). Исследователи описывают ряд технологических, экономических, социальных и политических механизмов, генерирующих модели затрат и выгод, при которых властные акторы сохраняют статус-кво институтов для выгоды в долгосрочной перспективе (Alexander 2001). Чем длительнее сохраняется статус-кво, тем более непривлекательны изменения, и первоначальный выбор воспроизводится заново (Collier, Collier 2002). Объяснение этому находится в механизмах обратной связи, посредством 
которых субъекты получают все большую выгоду от поведения, основанного на приобретенном ранее опыте (Deeg 2005: 22).

Теория институционализма описывает влияние исторических и институциональных факторов на структурирование взаимодействий множества акторов, приводящих к различным политическим результатам (Hall, Taylor 1996; Goldstein 1988). Авторы, работающие в этом направлении, представляют институциональное развитие как устойчивую зависимость свойств институтов от предшествующего опыта развития. Принятие новых целей без учета наследия институтов неэффективно и приводит к сопротивлению институтов, зависящих в то же время от глобальных социально-экономических или политических изменений, способных провоцировать конфликты интересов и влиять на эффективность вовлеченных в конфликт структур (Steinmo et al. 1992; Weir 1992). Сильные институты «душат» любые изменения (Mokyr 1992), что объясняется самой природой институтов- укоренившихся правил и обычаев, структурирующих взаимодействие (North 1990). Устойчивая зависимость от прошлого опыта определяет функционирование институтов: даже при изменившейся модели социальной политики и политическом режиме в РФ в 2000-х гг. сохраняются прежние свойства и нормы институтов, что делает особенно важной такую характеристику, как устойчивость.

Для инерционных характеристик важна идея институциональной непрерывности - повторяющегося социального порядка, выраженного в правилах и нормах институтов. Считается, что непрерывность «нормальна» для институтов, так как их деятельность сопротивляется изменениям в связи с ее рутинными процедурами. Гарри Сминиа определяет непрерывность как социальный механизм, возникающий в процессе осуществления институциональных практик для их исправления или снижения возможности их изменений (Sminia 2011: 1570). Институциональные акторы участвуют в конкретных практиках - деятельности по соблюдению норм и правил и воспроизведению институтов, в противном случае происходит переход от непрерывности к изменениям.

В рамках этой идеи важными компонентами являются влияние рутинных процедур на непрерывность локальных норм и правил институтов и их закрепление на длительный период времени. Учитывая эти наработки, в статье предлагается определить институциональную инерцию как свойство, приводящее к непрерывному сохранению институтов, устойчивости их ключевых норм и правил, а также стремящееся корректировать институциональные изменения и нововведения.

\section{Источники данных и методология исследования}

Источниками данных в этом исследовании являются законодательство о социальной защите инвалидов, постановления и распоряжения правительства о финансировании ВОИ, ВОС, ВОГ (Постановления Правительства РФ 
1995, 2000, 2006, 2007a, 2007b, 2009a, 2009b, 2010; Распоряжения Правительства РФ 2011, 2012, 2013, 2014, 2015, 2016, 2017, 2018), ежегодные отчеты о деятельности всероссийских обществ и справочные материалы с веб-сайтов организаций (ВОГ 2020; ВОИ 2020а, ВОИ 2020b; ВОС 2020), три глубинных интервью с представителями региональных подразделений ВОИ, ВОС, ВОГ Санкт-Петербурга (одно интервью проведено с помощью переводчика жестового языка). Данные о деятельности обществ неоднородны. ВОИ публикует отчеты на сайте общества с 2006 г., а ежегодный обзор деятельности с 2013 г. ВОС размещает отчетность о работе с 2011 г., а с 2017 г. информирует об итогах реабилитации инвалидов по зрению в ежегодных постановлениях. ВОГ публикует отчеты о деятельности с 2010 по 2015 гг., далее для анализа доступны только публицистические журналы «В едином строю» и «Мир глухих». ВОС и ВОГ не публикуют ежегодные обзоры своей деятельности, ограничиваясь информацией, предоставляемой к съезду региональных организаций, и отчетами региональных подразделений.

Для выявления индикаторов инерции проведен анализ деятельности ВОИ, ВОС, ВОГ по взаимодействию с государственными органами в контексте социальной защиты инвалидов. По итогам изучения отчетных документов о результатах деятельности обществ инвалидов, архивных материалов, статей составлена матрица ключевых практик, способствующих инерции институтов. Данные практики операционализированы в два индикатора инерции - устойчивость и непрерывность. Устойчивость представлена способностью объекта длительно сохранять свои свойства в определенной системе до наступления критического момента. Непрерывность описывает способность объекта сохранять институциональные практики посредством консервации их ключевых элементов, снижением возможности их изменений и исправлением противоречий (табл. 1).

Таблийа 1

Матрица ключевых инерционных практик ВОИ, ВОС, ВОГ

\begin{tabular}{ll}
\multicolumn{1}{c}{$\begin{array}{c}\text { Индикаторы } \\
\text { инерции }\end{array}$} & \multicolumn{1}{c}{$\begin{array}{c}\text { Деятельность по взаимодействию ВОИ, ВОС, } \\
\text { ВОГс органами власти }\end{array}$} \\
\hline Устойчивость & $\begin{array}{l}\text { Финансовая поддержка обществ от федеральных органов исполнитель- } \\
\text { ной власти } \\
\text { Предоставление в безвозмездное пользование имущества } \\
\text { Законодательно закрепленное участие обществ в консультативных } \\
\text { структурах по вопросам инвалидности }\end{array}$ \\
\hline Непрерывность & $\begin{array}{l}\text { Использование государственных льгот и субсидий как основного } \\
\text { источника финансирования обществ } \\
\text { Регулярное информирование власти о существующих проблемах } \\
\text { инвалидов конкретного общества } \\
\text { Внесение изменений в законодательство, дающих преимущества ВОИ, } \\
\text { ВОС, ВОГ в различных сферах }\end{array}$ \\
\hline
\end{tabular}




\section{Устойчивость и непрерывность во взаимодействии ВОИ, ВоС, вог и органов власти}

Основными формами взаимодействия ВОИ, ВОС, ВОГ и органов власти по вопросам социальной защиты людей с инвалидностью являются информационная, консультативная, финансовая и имущественная поддержка. Наличие индикаторов «устойчивость» и «непрерывность» проверялось в обозначенных формах взаимодействия каждого общества с органами власти с 2006 по 2019 гг. (в случае финансовой поддержкис 1996 г.) через анализ документов- отчетов о деятельности организаций, законодательных актов- и глубинных интервью.

Информационная поддержка. Устойчивость и непрерывность норм и правил прослеживаются в оказании информационной поддержки. С 1990-х гг. общества привлекают своих членов к участию в различных мероприятиях, собирая информацию об их проблемах, приглашают к участию органы власти и передают им собранную информацию, привлекая внимание государства к своим подопечным:

Мы провели большую работу со Сбербанком по созданию приложения. Это большая работа с разработчиками приложений, а потом по обучению людей < ..> со специалистами МФЦ мы проводим онлайн курсы по обучению пользования «Госуслугами» (м., представитель ВОС, СПб).

ВОИ сфокусировано на информировании о проблемах ратификации конвенции о правах инвалидов, защите молодых семей и детей инвалидов, проблемах проживания в стационарных учреждениях социального обслуживания и медико-социальной экспертизы (МСЭ). ВОГ же освещает проблемы в законодательстве о санаторном лечении, в обучении лиц с проблемами слуха, барьеры во внедрении русского жестового языка (РЖЯ), обучении переводчиков РЖЯ и получении услуг по переводу. Обществами регулярно проводятся массовые мероприятия- «ИнваЭкспо», «Мир равных возможностей», «Всероссийский образовательный реабилитационный форум ВОС», направленные на информирование инвалидов о новых технических средствах реабилитации (ТСР), освещение доступности городских инфраструктур, развитие интернетресурсов и региональных практик (ИнваЭкспо 2020; Мир равных возможностей 2020; Аудиодневники форумов ВОС 2020). При информировании о проблемах отмечается непрерывность практик выстраивания личных связей:

С председателем комитета по социальной политике можно договориться о встрече, но тут играет человеческий фактор, так как мы с ним давно знакомы... Личные отношения играют огромное значение, это однозначно (м., представитель ВОИ, СПб).

Таким образом, фиксируется устойчивость и непрерывность практик по ежегодному информированию власти о проблемах инвалидов с помощью 
специальных мероприятий и отчетных документов, сохранение ключевых практик по выстраиванию личных отношений.

Консультативная поддержка. На протяжении исследуемого периода общества участвуют в принятии политических решений посредством внесения поправок и изменений в законопроекты, регламентирующие социальную защиту людей с инвалидностью и законодательство о некоммерческих организациях и субъектах предпринимательства. Активнее в обсуждении политических решений действует ВОИ, так как председатель общества является депутатом и участвует в работе Государственной думы РФ: «В Госдуме от ВОИ есть Терентьев, и наше общество через него пытается лоббировать вопросыл (м., представитель ВОГ, СПб). С 2010 г. ВОИ участвует в разработке законопроекта госпрограммы «Доступная среда» и ее продлении до 2020 г., вносит замечания и комментарии о внедрении норм Конвенции о правах инвалидов в российские законодательные акты, о совершенствовании МСЭ и обеспечении инвалидов ТСР, об образовании и трудоустройстве, об обеспечении пенсиями и доступности приоритетных объектов и структур.

Общество регулярно оказывает консультативную поддержку властям в организации доступности для инвалидов спортивных сооружений и прилегающей к ним территории (ВОИ 2020b). С 2011 г. ВОС, ВОГ регулярно участвуют в совершенствовании МСЭ и внесении замечаний по региональным программам социальной поддержки инвалидов. С 2016 г. региональные подразделения ВОИ, ВОС, ВОГ участвуют в деятельности советов по делам инвалидов в законодательных органах власти, деятельности общественной палаты, комиссиях по доступной среде:

ВОГ и другие общества входят в координационный совет при губернаторе. Совет проходит два раза в год, но бывают незапланированные встречи с другими структурами (м., представитель ВОГ, СПб).

ВОГ участвует в роли эксперта в совещаниях о ТСР и организации перевода РЖЯ, тифлосурдоперевода, медико-социальной реабилитации пациентов после кохлеарной имплантации. Общество слепых постоянно проводит мониторинг объектов социальной, инженерной, транспортной и информационной инфраструктур на предмет их доступности для инвалидов по зрению. В последние годы продолжается консультирование по вопросам социально-бытовой реабилитации, доступности, обучения информационным технологиям:

Я вхожу в совет при избирательной комиссии города, мы вместе с ВОИ и ВОС обсуждаем вопросы, как сделать доступными для инвалидов выборы (м., представитель ВОГ, СПб).

Несмотря на устойчивую и непрерывную консультативную поддержку участие ВОИ, ВОС, ВОГ в принятии политических решений по вопросам инвалидности формально: 
Многим необходимы социальные услуги, оплачиваемые самостоятельно, а для пенсионеров бесплатные. Мы ставим вопрос перед властью, переписываемся с губернатором, председателем законодательного собрания - все отписались и всё возвращается обратно. Этот «футбол» ни к чему хорошему не приводит (м., представитель ВОИ, СПб).

Таким образом, артикулируемые обществами замечания и комментарии не привлекают внимания органов власти и редко учитываются при принятии важных политических решений.

Имущественная поддержка. Непрерывность и устойчивость имущественной поддержки всероссийских обществ закреплена на законодательном уровне с 2010 г. посредством предоставления льготных условий на выплаты ЖКХ и коммуникационных услуг для СО НКО (ФЗ № 40), льгот по налогообложению для их земельных участков (НК РФ ст. 395), предоставления государственного или муниципального имущества для уставной деятельности подразделений и предприятий (Ф3 № 110). На основании законодательства с 2006 г. местные органы власти предоставляют помещения центральным правлениям обществ и их региональным отделениям для организации и проведения социокультурных, образовательных, реабилитационных мероприятий и услуг, что в итоге приводит к проблемам:

Администрация считает, что мы должны поддерживать здание. Но мы сами не можем принимать решения, здание историческое, и денег на ремонты у нас нет... Надеемся на то, что город должен чем-то помочь, найти пути решения (м., представитель ВОГ, СПб).

Представители организаций утверждают, что имущественной поддержки недостаточно: «Большинство районных организаций имели свои помещения, но сейчас не в состоянии их обслуживать. Администрации районов могут предоставить только комнату, и то на 1-2 раза в неделю» (м., представитель ВОИ, СПб).

На федеральном уровне поддержка представлена передачей зданий и земельных участков, находящихся в федеральной собственности на территории республики Крым, в собственность ВОС и ВОГ на безвозмездной основе (Брыксин 2019). Представленные примеры аргументируют устойчивость и непрерывность имущественной поддержки.

Финансовая поддержка. Устойчивость и непрерывность практик по финансовой поддержке прослеживается посредством ежегодных субсидий ВОИ, ВОС, ВОГ от государства через профильные министерства. В рамках исследования выявлено 17 случаев, представленных законодательными актами, делегирующими всероссийским обществам субсидии из федерального бюджета страны (Постановления Правительства РФ 1995, 2000, 2006, 2007a, 2007b, 2009a, 2009b, 2010; Распоряжения Правительства РФ 2011, 2012, 2013, 2014, 2015, 2016, 2017, 2018). 


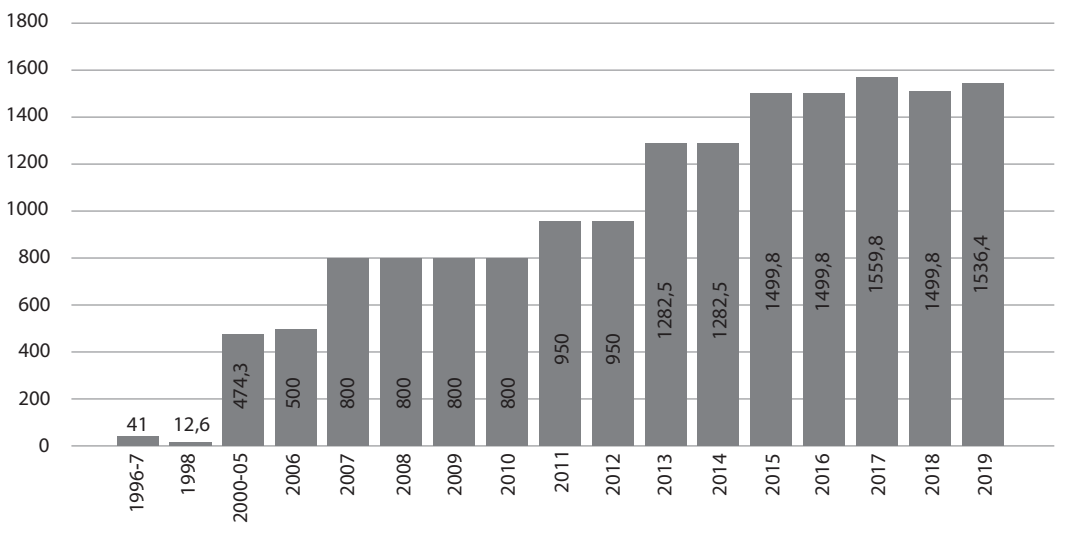

Рисунок 1.Предоставление субсидий ВОИ, ВОС, ВОГ, Инвалиды войны с 1996 по 2019 гг. в млн руб.

Анализ законодательных актов с 1996 по 2000 гг. выявил, что финансирование всероссийских обществ происходило в рамках программы «Социальная поддержка инвалидов». Программа на 2000-2005 гг. привлекла средства как бюджетов субъектов РФ, так и самих обществ, государственных фондов и других внебюджетных источников, при этом ВОИ, ВОС, ВОГ участвовали в разработке программы и в её реализации. На протяжении пяти лет государство выделило 474,3 млн руб. на финансовую поддержку организаций. Сумма направлена на осуществление экспертных работ (изучение информации о структуре и потребностях инвалидов), реконструкцию и поддержку санаториев и предприятий обществ. Длительная поддержка способствовала стабилизации экономического положения обществ и закрепила практики ежегодного финансирования организаций. В 2006 г. выделено 500 млн руб., помимо исследуемых организаций, государство финансировало общественную организацию инвалидов войны в Афганистане, однако её поддержка прекратилась в 2018 г., из-за множества нарушений. С 2007 по 2010 гг. субсидии возросли с 500 до 800 млн руб. в связи с инфляцией. Финансирование обществ до 2010 г. не изменялось - основная часть бюджета распределялась на ВОИ и ВОС, меньшие суммы получал ВОГ и Инвалиды войны. В 2011 г. финансирование увеличилось из-за программы «Доступная среда», которая используется как ресурс для организации мероприятий и покупки оборудования в региональных отделениях обществ. С 2011 г. выявлена тенденция к изменению выделяемой суммы: власти оценивают результаты деятельности всероссийских обществ и корректируют цифры бюджета. В 2018 г. сумма субсидий снижена до 1499,8 млн, а в 2019 г. увеличена до 1536,4 млн руб. и распределена только между ВОИ, ВОС, ВОГ. Однако в любом случае распределяемые средства не удовлетворяют потребностей региональных подразделений обществ: 
С моей точки зрения, общероссийским организациям инвалидов, имеющим имущественный и кадровый потенциал, должны быть отдельные субсидии на уровне региона (м., представитель ВОС, СПб).

Устойчивость и непрерывность финансирования прослеживается в государственной поддержке хозяйственных предприятий обществ. Так, предприятия ВОИ, ВОС, ВОГ не смогли конкурировать с другими в условиях новой модели социальной политики, аутсорсинга и госзаказа, но попытались частично зафиксировать право на адресную поддержку при помощи законодательства:

У нас была ООО «Пальмира»- обработка металла, производство упаковок, пошив одежды. Предприятие не смогло конкурировать и обанкротилось без госзаказов. Сейчас предприятия сохранились у ВОС, они получают заказы от администрации и государства (м., представитель ВОГ, СПб).

Исключительным случаем влияния ВОИ, ВОС, ВОГ на политический курс в 2019 г. стало принятие поправок в Ф3 № 185, приравнивающих предприятия обществ к статусу субъектов малого предпринимательства и предоставляющих предприятиям ВОИ, ВОС, ВОГ и их территориальным подразделениям возможность получения финансового преимуществане менее $15 \%$ госконтрактов без конкуренции (Ф3 № 185). Этот редкий пример законодательства, предусматривающего конкурсные принципы финансирования и закрепляющего старые принципы целевой поддержки, показывает сохранение инерции предыдущих практик финансирования ВОИ, ВОС, ВОГ, несмотря на изменение модели социальной политики. К описанным инерционным практикам привносятся и прогрессивные способы поддержки-участие в конкурсных процедурах, однако переход к их использованию у ВОИ, ВОС, ВОГ происходит болезненно.

\section{Заключение}

На примере взаимодействия органов власти и всероссийских обществ инвалидов продемонстрировано проявление институциональной инерции в контексте социальной защиты людей с инвалидностью. Анализ теоретических идей и концептов определил феномен инерции и операционализировал его с помощью индикаторов устойчивости и непрерывности. Исследование показывает неизменное воспроизводство практик государственной поддержки всероссийских обществ инвалидов на протяжении длительного времени.

Выявленные индикаторы подтверждают наличие институциональной инерции во взаимодействии всероссийских обществ инвалидов с государственной властью. Однако черты инерции во взаимодействии с государством проявляются по-разному в каждом обществе, непрерывность информационной 
и консультативной поддержки неприменима ко всем структурам власти. Наиболее инертной формой взаимодействия в каждом обществе является финансовая поддержка. ВОИ, ВОС, ВОГ обладают сложной структурой, и было бы неверно говорить об их абсолютной инертности. Вместе с инерцией возникают попытки инноваций-внедрение электронного документооборота, организация образовательных и культурно-досуговых мероприятий онлайн, вызванные современной повесткой дня. Данная статья является первым шагом исследования инерции институтов российской социальной политики. Признание этой проблемы внесет ясность в состояние современной повестки о вопросах инвалидности и позволит определить механизмы воспроизведения феномена инерции.

\section{Выражения признательности}

Исследование выполнено при финансовой поддержке РФФИ в рамках научного проекта № 19-311-90026.

\section{Материалы для анализа}

Аудиодневники форумов ВОС (2020) Доступно по ссылке: http://www.radiovos. ru/1314598867783041.html (дата обращения: 29 апреля 2020).

Брыксин (2019) Закон создает правовой механизм передачи земельных участков, принадлежащих организациям инвалидов. Доступно по ссылке: https://bryksin.ru/ article/2019/10/17/Bryksin-Zakon-sozdaet-pravovoj-mexanizm-peredachi-zemelnyxuchastkov-pr?id=10837 (дата обращения: 2 мая 2020).

ВОГ (2020) Документы Доступно по ссылке: https://voginfo.ru/about/docs/ (дата обращения: 20 февраля 2020).

ВОИ (2020a) Отчеты Доступно по ссылке: http://www.voi.ru/dokumenty/otchety (дата обращения: 15 февраля 2020).

ВОИ (2020b) О законодательной работе в Государственной Думе ФС РФ Доступно по ссылке: http://www.voi.ru/news/novosti_strany/predsedatel_voi_mihail_terentev_ prinyal_uchastie_v_rabote_privolzskogo_mrs_voi.html (дата обращения: 2 мая 2020).

ВОС (2020) Справочные материалы Доступно по ссылке: https://www.vos.org.ru/ index.php?option=com_content\&view=category\&id=421\&Itemid=449(дата обращения: 17 февраля 2020).

ИнваЭкспо (2020) Доступно по ссылке: http:/www.voi.ru/meropriyatiya/my_priglahaem/ invaekspo_obshestvo_dlya_vseh.html (дата обращения: 28 апреля 2020).

Мир равных возможностей (2020) Доступно по ссылке: http://mirrv.ru/archiv/ (дата обращения: 28 апреля 2020).

Налоговый кодекс РФ (часть вторая) статья 395. Налоговые льготы № 117-Ф3 от 05.08.2000 г. 
Постановление Правительства РФ (1995) О федеральной комплексной программе «Соииальная поддержка инвалидов № 59 от 16.01.1995 г.

Постановление Правительства РФ (2000) О федеральной иелевой Программе «Соичальная поддержка инвалидов на 2000-2005 годыр» № 36 от 14.01.2000 г.

Постановление Правительства РФ (2006) Об утверждении правил предоставления и использования в 2006 году субсидий из федерального бюджета на государственную поддержку общероссийских общественных организаичий инвалидов № 463 от 26.07.2006 г.

Постановление Правительства РФ (2007a) Об утверждении Правил использования средств федерального бюджета, предусмотренных в 2007 году на государственную поддержку общероссийских общественных организаиий инвалидов № 486 от 27.07.2007 г.

Постановление Правительства РФ (2007b) Об утверждении Правил предоставления в 2008 году субсидий из федерального бюджета на государственную поддержку общероссийских общественных организаций инвалидов № 974 от 29.12.2007 г.

Постановление Правительства РФ (2009а) Об утверждении Правил предоставления в 2009 году субсидий из федерального бюджета на государственную поддержку общероссийских общественных организаций инвалидов № 96 от 04.02.2009 г.

Постановление Правительства РФ (2009b) Об утверждении Правил предоставления в 2010 году субсидий из федерального бюджета на государственную поддержку общероссийских общественных организаиий инвалидов № 1067 от 22.12.2009 г.

Постановление Правительства РФ (2010) О предоставлении субсидий из федерального бюджета на государственную поддержку общероссийских общественных организаций инвалидов в 2011 году № 1074 от 20.12.2010 г.

Распоряжение Правительства РФ (2011) Об утверждении прилагаемого распределения субсидий из федерального бюджета на государственную поддержку общероссийских общественных организачий инвалидов в 2012 году № 2278-р от 21.12.2011 г.

Распоряжение Правительства РФ (2012) О распределении в 2013 году субсидий из федерального бюджета на государственную поддержку общероссийских общественных организаций инвалидов № 2418-р от 17.12.2012 г.

Распоряжение Правительства РФ (2013) Об утверждении распределения субсидий, предоставляемых в 2014 году из федерального бюджета на государственную поддержку общероссийских общественных организащий инвалидов № 2398-р от 18.12.2013 г.

Распоряжение Правительства РФ (2014) Об утверждении распределения субсидий, предоставляемых в 2015 году из федерального бюджета на государственную поддержку общероссийских общественных организаций инвалидов № 2547-р от 15.12.2014 г.

Распоряжение Правительства РФ (2015) О распределении субсидий, предоставляемых в 2016 году из федерального бюджета на государственную поддержку общероссийских общественных организаций инвалидов № 2672-р от 25.12.2015 г.

Распоряжение Правительства РФ (2016) О распределении субсидий, предоставляемых в 2017 году из федерального бюджета на государственную поддержку общероссийских общественных организаций инвалидов № 2768-р от 22.12.2016 г. 
Распряжение Правительства РФ (2017) О распределении субсидий, предоставляемых в 2018 году на государственную поддержку общероссийских общественных организаций инвалидов № 2856-р от 16.12.2017 г.

Распоряжение Правительства РФ (2018) О распределении средств, предоставляемых в 2019 году на государственную поддержку общероссийских общественных организаций инвалидов № 2919-р от 24.12.2018 г.

Федеральный закон (1995) О социальной защчите инвалидов в Российской Федераиии № 181-ФЗ от 24.11.1995 г.

Федеральный закон (2010) О внесении изменений в отдельные законодательные акты Российской Федерации по вопросу поддержки сочиально ориентированных некоммерческих организаций № 40-ФЗ от 05.04.2010 г.

Федеральный закон (2012) О внесении изменений в статьи 4 и 33 Ф3 «О сочииальной защите инвалидов в Российской Федерации» и Ф3 «Об общиих принщиипах организаџии местного самоуправления в Российской Федеращии» № 110-ФЗ от 10.07.2012 г.

Федеральный закон (2019) О внесении изменений в статью 33 Федерального закона «O социальной защчите инвалидов в Российской Федерации» и статьи 4 и 4.1 Федерального закона "О развитии малого и среднего предпринимательства в Российской Федераиии» № 185-ФЗ от 18.07.2019 г.

\section{Список источников}

Малева Т.М., Авраамова Е.М. (2017) Альтернативы развития социальной защиты населения. Журнал исследований соичальной политики, 15 (4): 559-572.

Alexander G. (2001) Institutions, Path Dependence, and Democratic Consolidation. Journal of Theoretical Politics, 13 (3):249-269.

Campbell J. (2010) Institutional Reproduction and Change. In: G. Morgan, J. L. Campbell, C. Crouch, O.K. Pedersen, R. Whitley (eds.) The Oxford Handbook of Comparative Institutional Analysis. Oxford: Oxford University Press: 87-115.

Collier R., Collier D. (2002) Shaping the Political Arena: Critical Junctures, the Labor Movement, and Regime Dynamics in Latin America. Notre Dame: University of Notre Dame Press.

Deeg R. (2005) Complementarity and Institutional Change: How Useful a Concept? WZBmarkets and Politics Working Paper No. SP II, 21.

Fröhlich C., Skokova Y. (2020) Two for One: Public Welfare and Regime Legitimacy Through State Funding for CSOs in Russia. VOLUNTAS: International Journal of Voluntary \& Nonprofit Organizations, 31 (4):698-709.

Goldstein J. (1988) Ideas, Institutions, and American Trade Policy. International Organization, 42 (1): 179-217.

Hall P., Taylor R. (1996) Political Science and the Three New Institutionalisms. Political studies, 44 (5): 936-957.

Lane J. (2000) New Public Management: An Introduction. London: Routledge. 
Mahoney J., Thelen K. (2010) A Theory of Gradual Institutional Change. Explaining Institutional Change: Ambiguity, Agency, and Power, (1): 1-37.

Mokyr J. (1992) Technological Inertia in Economic History. The Journal of Economic History, 52 (2): 325-338.

North D. (1990) Institutions, Institutional Change and Economic Performance. Cambridge: Cambridge University Press.

Pierson P. (2000) Increasing Returns, Path Dependence, and the Study of Politics. American Political Science Review, 94 (2): 251-267.

Sminia H. (2011) Institutional Continuity and the Dutch Construction Industry Fiddle. Organization Studies, 32 (11): 1559-1585.

Steinmo S., Thelen K., Longstreth F. (eds.) (1992) Structuring Politics: Historical Institutionalism in Comparative Analysis. Cambridge: Cambridge University Press.

Tarasenko A. (2018) Russian Non-Profit Organisations in Service Delivery: Neoliberal and Statist Social Policy Principles Intertwined. Europe-Asia Studies, 70 (4): 514-530.

Weir M. (1992) Ideas and the Politics of Bounded Innovation. Structuring Politics: Historical Institutionalism in Comparative Analysis, 8 (1): 188-216. 
Aleksandr Bugrovskii

\title{
ALL-RUSSIAN SOCIETIES OF PEOPLE WITH DISABILITIES: THE NATURE OF INERTIA IN INTERACTION WITH STATE AUTHORITIES
}

\begin{abstract}
This paper investigates the phenomenon of inertia in the interaction of the state and all-Russian Societies of the Disabled. The Russian context retains conservative trends in the state cooperation with NGOs, which is marked by paternalism and categorical assistance for disabled, formalism inherent in consultations with the state authorities. Along with this, there is the development of social services and their suppliers, innovations in the framework of the new public administration policy. The state is focused on developing the third sector, however, all-Russian societies hardly fit into the current model of social policy. They successfully preserve their own structures and established forms of interaction with authorities. Hence we find duality in the social protection of the disabled such as inertia in attempts to reform this system. The central questions of this article are: what is the character of this inertia and why do all-Russian societies of the disabled still exist in their old form regardless of the changing context? The article scrutinises how institutional inertia manifested itself by considering the interaction of the state and the All-Russian Societies of the Disabled, Blind, and Deaf in the context of social welfare. An analysis of theories of historical institutionalism, path dependence, and the idea of institutional continuity helps define the term of institutional inertia. Then indicators of inertia are operationalized. The empirical sources include legislation, societies' documents on funding, in-depth interviews, media articles and annual reports from 1996 to 2019. The discovered inertia in Russian institutions help to clarify the continuities of disability policies agenda and determine the mechanisms for reproducing inertia.
\end{abstract}

Key words: social protection, NGOs, new public management, institutional inertia, people with disability

DOI: 10.17323/727-0634-2021-19-4-685-700

\section{References}

Alexander G. (2001) Institutions, Path Dependence, and Democratic Consolidation. Journal of Theoretical Politics, 13 (3):249-269.

Campbell J. (2010) Institutional Reproduction and Change. In: G. Morgan, J. L. Campbell, C. Crouch, O.K. Pedersen, R. Whitley (eds.) The Oxford Handbook of Comparative Institutional Analysis. Oxford: Oxford University Press: 87-115.

Aleksandr Bugrovskii - Intern-Investigator, The Center of Comparative Studies of Power and Governance, Higher School of Economics, Saint Petersburg, Russian Federation. Email: abugrovskiy@hse.ru 
Collier R., Collier D. (2002) Shaping the Political Arena: Critical Junctures, the Labor Movement, and Regime Dynamics in Latin America. Notre Dame: University of Notre Dame Press. Available at: ssrn.com/abstract $=2769109$ (accessed $18^{\text {th }}$ November 2020$)$

Deeg R. (2005) Complementarity and Institutional Change: How Useful a Concept? WZBmarkets and Politics Working Paper No. SP II, 21.

Fröhlich C., Skokova Y. (2020) Two for One: Public Welfare and Regime Legitimacy Through State Funding for CSOs in Russia. VOLUNTAS: International Journal of Voluntary \& Nonprofit Organizations, 31 (4):698-709.

Goldstein J. (1988) Ideas, Institutions, and American Trade Policy. International Organization, 42 (1): 179-217.

Hall P., Taylor R. (1996) Political Science and the Three New Institutionalisms. Political studies, 44 (5): 936-957.

Lane J. (2000) New Public Management: An Introduction. London: Routledge.

Maleva T.M., Avraamova E. M. (2017) Al'ternativy razvitiya sotsial'noy zashchity naseleniya [The Development of Alternatives of Social Protection System]. Zhurnal Issledovanii Sotsial'noi Politiki [The Journal of Social Policy Studies], 15 (4).

Mahoney J., Thelen K. (2010) A Theory of Gradual Institutional Change. Explaining Institutional Change: Ambiguity, Agency, and Power, (1): 1-37.

Mokyr J. (1992) Technological Inertia in Economic History. The Journal of Economic History, 52 (2): 325-338.

North D. (1990) Institutions, Institutional Change and Economic Performance. Cambridge: Cambridge University Press.

Pierson P. (2000) Increasing Returns, Path Dependence, and the Study of Politics. American Political Science Review, 94 (2): 251-267.

Sminia H. (2011) Institutional Continuity and the Dutch Construction Industry Fiddle. Organization Studies, 32 (11): 1559-1585.

Steinmo S., Thelen K., Longstreth F. (eds.) (1992) Structuring Politics: Historical Institutionalism in Comparative Analysis. Cambridge: Cambridge Univer

Tarasenko A. (2018) Russian Non-Profit Organisations in Service Delivery: Neoliberal and Statist Social Policy Principles Intertwined. Europe-Asia Studies, 70 (4): 514-530.

Weir M. (1992) Ideas and the Politics of Bounded Innovation. Structuring Politics: Historical Institutionalism in Comparative Analysis, 8 (1): 188-216. 